\title{
Giorgio Fiocco: a jolly good fellow and his research
}

\author{
Glauco Benedetti-Michelangeli $(*)$, Marco Cacciani $\left({ }^{1}\right)$, Anna Capasso $\left({ }^{2}\right)$, Fernando Congeduti $\left({ }^{3}\right)$, \\ Tatiana Di Iorio $\left({ }^{1}\right)$, Alcide G. di Sarra $\left({ }^{1}\right)\left({ }^{4}\right)$, Daniele Fuà $\left({ }^{1}\right)\left({ }^{5}\right)$, Gerald Grams $\left({ }^{6}\right)$, \\ George Magyar $(*)$, Giandomenico Pace ${ }^{1}$ ) and Guido Visconti $\left({ }^{7}\right)$ \\ ( ${ }^{1}$ ) Dipartimeno di Fisica, Università di Roma «La Sapienza», Roma, Italy \\ $\left(^{2}\right)$ Ufficio Stampa, CNR, Roma, Italy \\ $\left(^{3}\right)$ Istituto di Scienze dell'Atmosfera e del Clima, Sezione di Roma, Italy \\ ${ }^{4}$ ) ENEA, CLIM-OSS, S. Maria di Galeria, Italy \\ $\left({ }^{5}\right)$ DISAT, Università di Milano-Bicocca, Milano, Italy \\ $\left(^{6}\right)$ Atlanta University, Atlanta, GA, U.S.A. \\ ( $\left.{ }^{7}\right)$ Dipartimento di Fisica, Università dell'Aquila, Italy
}

\begin{abstract}
In celebrating the 70th birthday of Giorgio Fiocco we recall that his scientific production includes some pioneering work in a number of fields where he set important milestones. In particular, several of his papers represent the first published evidence in certain fields and triggered such a large flow of research, new developments and new paper production that the original source is almost forgotten. Here the topics where his contribution was of pioneering importance are briefly recalled and his original works cited.
\end{abstract}

Key words atmosphere-lidar-aerosol

\section{Introduction}

Since his thesis at the Faculty of Engineering of the University of Rome, Giorgio Fiocco has been extremely active in several fields of both Engineering and Physics. Here we do not need to acknowledge his already high visibility in the Italian and international academic and scientific community: his authority is well recognized by his participation in many committees and panels, as well as his affiliation in academies,

Mailing address: Prof. Daniele Fuà, Dipartimento di Fisica, Università di Roma «La Sapienza», P.le Aldo Moro 2, 00185 Roma, Italy; e-mail: fua@g24ux.phys.uniroma1.it

$(*) \ll$ Retired». scientific societies and, last but not least, his past positions as head of important research institutions (director of the former Institute of Atmospheric Physics, IFA, of the National Research Council, CNR, and president of the Italian Space Agency, ASI). Affirming that most people involved in atmospheric physics all over the world know who Giorgio Fiocco is is not an overstatement.

According to one of Fiocco's basic teachings that «quality is more important than quantity», his paper production is not as heavy (in a literal sense) as that of other colleagues in the physical sciences although it still numbers an outstanding 300 or so. Here we recall that among his scientific production one can find some pioneering work in a number of fields where he set important milestones. In particular, several of his papers represent the first published evidence in some fields and triggered such a large flow of research, new developments and new paper production that the original source is almost forgotten. 
The main aim of this paper written for celebrating his 70th birthday is to settle this point: to recall briefly the topics where the contribution of Giorgio Fiocco was of pioneering importance and cite his original works which confirm his primacy in order to reaffirm the true paternity of some ideas and techniques accepted worldwide.

\section{Great Britain}

Fiocco had just graduated as an Electrical Engineer in 1956; what could he become if not an employee of one of the «diamond tips» in the electronics industry at that time: the Marconi Company.

The fact that

i) going abroad for a job at that time was not common (during the Italian economic «boom» of the late fifties, job opportunities at home were abundant),

ii) the choice of the U.K. was even less common for Italians and

iii) the choice of working for the firm founded by a very famous and brilliant Italian inventor, may or may not be relevant. Surely it was the first (and, probably not easy) step forward in view of his next big jump overseas.

The facts are that he was right away involved in advanced research in Radar and navigational aid systems and his contribution was such that some of his discoveries were patented for Marconi (Fiocco,1958a-e, 1959a-e; Adam and Fiocco, 1959).

Being in private industry, his contributions at that time are published as Internal Reports. Moreover, most of the discoveries and developments which were the ultimate thing at that time, are probably nowadays outdated by any of the computer chips that control our kitchen appliances (on the relationship between the scientific knowledge of different generations of students, in this same issue, there is an interesting essay by L. Smullin, a teacher and good friend of Fiocco's).

Of his «science» there, we, friends and atmospheric physicists, do not have much record. What we believe is that Marconi's, like England, was the training entrancehall where Fiocco first came in touch with the true, «dirty» world and its fascinating applied sciences after his book-based university years. Since then the enchantment of such devices as Radars, able to sense far objects, never left him and always spurred his knack for practical and brilliant solutions to new and challenging problems.

In particular, he was interested in a deeper understanding of what professional radar people consider noise but is indeed the atmospheric signature. At that time it probably occurred to Giorgio Fiocco that studying the source of the radar noise could become a new branch of the geophysical sciences.

\section{United States}

We must face it that to be successful in scientific research it is not often sufficient to be talented, one needs certain amount of luck: to be at the right place at the right time. This was the case in the laser field in the early sixties. The first laser was constructed in 1960 in the U.S. During the next 2-3 years various types of lasers, laser effects and applications were discovered or invented, each of which became the foundation of a whole new research field. Two of these were associated with the name of Giorgio Fiocco. He, like many young European researchers, went to the United States in order to perfect his research skills and learn the latest techniques.

One of the outstanding professors of the Electrical Engineering Department at MIT was Louis Smullin, formerly a member of the Radiation Laboratory of the same university where the microwave Radar had been developed. Smullin chose young Fiocco to set up an active optical instrument able to measure the distance from the Moon: one of the first optical radar or LIDAR (acronym for LIght Detection And Ranging, an obvious readjustment of the acronym RADAR, RAdio Detection And Ranging). When one considers how difficult is was to observe a few photons of laser light reflected from the lunar surface without the benefit of the retro-reflector placed much later on the Moon by astronauts, everybody can appreciate the sense of humor in the chosen code name used for the lunar ranging program - «Project Luna See» sounds 
like «project lunacy». After struggling with electronics that nowadays can be seen only in science museums, they got the first light pulses echoed from a half Moon during three nights of May 1962. The news was soon highlighted in newspapers all over the world (it made the first page in the New York Times); in particular, the scientific report was published in the outstanding journal Nature (Smullin and Fiocco, 1962).

Next came the application of laser pulses to diagnose a plasma by Thomson scattering (Fiocco and Thompson, 1963). The advantages of laser light are: negligible disturbance of the plasma, high spatial and temporal resolution (a very short laser pulse is used), remoteness from the plasma. At the same time, the laser beam is sufficiently powerful to produce observable effects. In the case of the Thomson scattering the originally narrow spectrum becomes broadened after interacting with the hot electrons of the plasma. The broadening is directly proportional to the temperature and the amount of light scattered depends on the plasma density, thus providing information on the two most important parameters of a plasma while the centroid of the spectrum provides a measurement of the radial bulk velocity of the medium. Lasers became the standard diagnostic tools for fusion plasmas all over the world, finding many other applications, but Fiocco's was indeed the pioneering paper.

In the experiments by Fiocco and Smullin (Fiocco and Smullin, 1963), laser echoes from the mesosphere were tentatively attributed to incoming micrometeorites (Fiocco and Colombo, 1964).

The presence of aerosol layers near or below the mesopause has been established by numerous visual observations of noctilucent clouds. Fiocco and Grams $(1966,1969)$ conducted lidar measurements at high latitudes where noctilucent clouds are observed.

Observations of transient features of a noctilucent cloud were also obtained during that experiment. Fiocco and Grams (1971) related latitudinal and seasonal changes in the vertical distribution of extraterrestrial particles below $100 \mathrm{~km}$ to the general circulation of the upper atmosphere. Estimates of the mass flux of extraterrestrial dust based on lidar data obtained at high latitudes (Fiocco and Grams, 1969) are in agreement with results obtained by other tech- niques (summarized, for example, by Parkin and Tilles, 1968).

It is interesting to recall that volcano Agung was timely enough, in 1963, to explode and inject into the atmosphere dust and gases, that would form in the lower stratosphere the liquid and solid targets to be detected by Giorgio Fiocco's lidars. The first application of lidars to study the stratospheric aerosol layer was the work of Fiocco and Grams (1964). The lidar could rapidly acquire backscattering profiles of the layer of aerosols found in the interval from 15 to $25 \mathrm{~km}$. These observations permitted the study of shortterm temporal variations in the aerosol layer. Stratospheric aerosol observations were made with a lidar operated at Lexington, Massachusetts, during 1964 and 1965 (Grams and Fiocco, 1967). Some observations were also conducted at College, Alaska, in the summer of 1964. Vertical profiles of aerosol concentration were obtained by dividing the backscattering coefficients measured with the lidar echoes by the expected return from a molecular atmosphere. The lidar «scattering ratios» introduced by Fiocco and Grams have been used extensively by other lidar groups since that time.

Other large volcanoes (St. Helens, in 1980; El Chichón, in 1984, and Pinatubo, in 1991) exploded during the following years, all at the right time to be monitored by lidar, and to prompt important research on stratospheric composition, dynamic, chemistry and radiation.

The work at Marconi's with Doppler Radars probably also triggered the idea that such technique applied to lidars would have made it possible to detect the velocity of the small light scatterers present in the atmosphere. In case such scatterers were large and dragged by the air, their average velocity would be equal to the wind velocity; if the scatterers were air molecules, their velocity distribution would be directly related to the gas temperature. The theoretical treatment of such phenomenon is extensively developed in an often cited paper of Fiocco and a bright young student: Fiocco and De Wolf (1968). At the same time he started working at the way to measure such properties in the laboratory. The first devices were built in the U.S. but soon he was called by ESRIN in the laboratory of Frascati and he was allowed to carry with him many of the already constructed devices. 
It is worth mentioning that in those first years at MIT, Fiocco conceived and literally designed for the laboratory a sort of optical «Meccano» that all his co-workers know very well. With the aid of a score of different modular pieces (a compromise between metric and anglo-american sizes but always perfectly fitting) precisely machined in anticorodal, bronze and steel on the original drawings of Fiocco, it has been possible, since then, to construct any kind of optical system. Such versatility is hardly found even in catalogues of important optics producers. Several of his former co-workers, who have continued their work in atmospheric optics by themselves, are still using Fiocco's «Meccano».

\section{Italy, Frascati}

As mentioned above, in 1969 Fiocco was called back to Italy to set up a group of atmospheric physics at ESRIN, a child laboratory of ESRO, born with great auspices that soon faded under the weight of diplomatic-political questions. The fact that ESRIN was in the neighborhood of Rome, famous for an inexplicably too abundant production of low-quality wine, has probably nothing to do with what happened next, but the laboratory eventually turned out to be quite short lived. One of its merits is that its wealth of funds, space and facilities, was the definitive bait that brought Giorgio Fiocco back to Italy. If it were not for that outstanding laboratory, Fiocco would probably still be in the U.S.

The Doppler effect on visible radiation had been known by astronomers since the beginning of the 20th century but the involved velocities were very high and the famed «red shift» of the expanding universe was easily studied. Conversely, the velocities involved in atmospheric physics requires a quite high instrument resolution not easily achieved.

The apparati like Radars which use radio frequencies that have the advantage of keeping their coherence, solve the problem by mixing the signal with a reference oscillator (homo- or hetero-dyne technique). Such technique shifts the frequency of the signal to be analyzed to a much lower range where the required resolution is more easily reached. Applying the same technique to optical frequencies is possible (and indeed is done) but has several limitations. Giorgio Fiocco at that time took the unltimate decision» that put him for good on one of the two exclusive parties of the lidar community: on one side the «coherent» Doppler lidar guys who use the mixing technique and on the other, the «incoherent» Doppler lidar guys who perform the analysis of the raw signal without any mixing. The effort from the second party to discourage being nicknamed «incoherent» by demonstrating that their method utilizes somehow light coherence as well, has gone unheard to date. Here, for sake of impartiality (which is not the case because some of us belong to this very side), the denigrating definition «incoherent technique» is called «direct detection technique».

The application of the direct detection technique for measuring the atmospheric temperature and wind, proposed and published for the first time by Fiocco, is based on the spectral scanning of the lidar echo signal with a very high resolution interferometer. Fiocco's idea was original also in proposing the use of an interferometer known in the hyperfine spectroscopy community but otherwise seldom used: the Fabry-Perot etalon. Typically a FabryPerot used to study hyperfine transition lines in laboratory experiments where there is abundance of signal has a diameter of 2 " or less; Giorgio Fiocco had special 4" plates made and coated for him with very high precision by a U.K. glass manufacturer. He designed from scratch also the mechanics that held the plates and made possible the frequency scanning either piezoelectrically or by pressure change.

In a search for the optimum light transmittance (although Fiocco, talking to his junior co-worker would often say that «optimum is the enemy of good»), with G. Benedetti-Michelangeli, he dug out of the books an even more obscure spectroscopic device: the spherical Fabry-Perot invented and studied by Connes (1958). At very high resolutions needed for the Doppler technique it can be demonstrated that confocal mirror cavities have a great advantage over at mirror cavities. $\mathrm{He}$ and his team made a whole series of different spherical Fabry-Perot cavities with impressive resolutions that allowed the measurement of the wind velocity with such accuracy to compute 
the turbulent eddy diffusion coefficient in the boundary layer.

The papers written in those years are the first record of utilizing the lidar Doppler technique in the atmosphere (Fiocco et al., 1971; BenedettiMichelangeli et al., 1972, 1974). Many years later when the lidar Doppler technique became a fashionable sort of topic in the international scientific community, the main problems involved were still the same and Fiocco had some solutions to suggest for following the drift of a laser line (Zuccheretti et al., 1992).

As with the two kinds of Fabry-Perot interferometers, he took another little known idea from the books and set it into use. An astronomer from Bologna Observatory, G. Horn-D'Arturo, had thought that instead of having a very expensive large area telescope built, he could use an array of properly made small telescopes (Horn-D'Arturo, 1935). The idea comes from the observation that due to the extreme difficulty of making large precise optical surfaces, the cost of many small mirrors was by far less than the cost of a large mirror with the same total area. At that time, mirror arrays were already used for solar furnaces or other non-optical grade applications, here the point was to obtain a telescope good for astronomers and, in the case of Fiocco, good for a lidar. Incidentally this idea is still valid and seems one of the better solutions for large telescopes in space.

In 1973, the $3 \mathrm{~m}$ mosaic telescope made of 36 hexagonal mirrors in a $12 \mathrm{~m}$ high tower adjacent the ESRIN laboratory started to collect the first lidar echoes from the stratosphere. A unique facility in the world. After going through few lifting jobs and passing from ESRIN to the Italian National Research Council (CNR), it worked and produced a fair amount of scientific results up to a few years ago (1999) when the laboratories were moved to a new site and the relocation of the tower was not considered economically viable. The building and some of the steel innards are still there like an old pharaoh's monument.

As previously mentioned, in $1980 \mathrm{Mt}$. St. Helens exploded, and in 1984 so did the volcano El Chichón. In the period following the eruptions, most of the lidars all around the world made measurements of the aerosol distribution and evolution in the stratosphere. The lidar in Frascati made measurements (Adriani et al., 1983), that were also used as ground truth for the Stratospheric Aerosol and Gas Experiment II (Ackerman et al., 1988). Studies on the interactions between aerosol and ozone in the stratosphere were also conducted (Adriani et al., 1987).

In the early to mid-1970s, Fiocco was a frequent visitor at the National Center for Atmospheric Research (NCAR) at Boulder, Colorado, where he worked with the «ol' good times» and great friend Gerry Grams on a series of papers involving the energetic equilibrium of small particles in the Earth's upper atmosphere. Aerosols absorb energy from the solar and planetary radiation fields, exchange energy by collisions with the ambient gas, and emit thermal radiation. Interactions with the atmospheric radiation field is a function of size and refractive index of the particles and of the spectral density and anisotropy of the radiation field. The heat exchanged through collisions is a function of the temperature and density of the ambient gas and of the temperature of the particles. Equilibrium conditions for any given particle size and composition are thereby functions of the altitude, time of day, season, and planetary albedo. Equilibrium particle temperatures can be substantially different from the ambient gas temperature; Fiocco et al. (1975) showed that the effects could be very large above $60 \mathrm{~km}$ where differences in excess of $100 \mathrm{~K}$ could be obtained in daytime. These differences could account for substantial increases in the sublimation rates of certain species (Fiocco and Visconti, 1973) and for a reduction in the altitude interval where ice particles could exist in the mesosphere (Grams and Fiocco, 1977). The identification of the role of aerosol on the atmospheric heating and on the photodissociation rates treated in those years with different colleagues (Fiocco et al., 1974, 1976, 1978; Mugnai et al., 1978, 1979; Petroncelli et al., 1980) constitutes one of the many fundamental contributions to the understanding of the atmospheric processes.

At the same time, he dedicated some efforts to the development of acoustic sounders (Mastrantonio and Fiocco, 1982), to the characterization of the atmospheric boundary layer (Fiocco and Mastrantonio, 1983), and to the combination of different techniques (Congeduti et al., 1981). 
In his neverending search for literally spioneering» challenging measurements, he deployed in person and with other adventurous co-workers an acoustic sounder on a ship cruising the Red Sea and, later, on one of the highest possible sites in Europe: Capanna Margherita on top of Mt. Rosa (4400 m a.s.1.).

In the same years of ESRIN Fiocco, using his expertise in optical spectroscopy, studied the properties of few minor atmospheric components such as $\mathrm{OH}$ (Fiocco et al., 1970; Visconti and Fiocco, 1970, 1973; Fiocco and Grams, 1971; Visconti et al., 1971; Fiocco and Visconti, 1973, 1974).

\section{Italy take 2: Rome}

In 1984, Fiocco started a new laboratory in the Department of Physics of the University of Rome. The first experiment in the laboratory was dedicated to the measurement of the ozone absorption cross section in the ultraviolet spectral range (Cacciani et al., 1989), and, later, in the visible (Amoruso et al., 1990). Of particular interest was the dependence on temperature. These measurements had been carried out by few groups previously. The small differences among the published measurements had a significant impact on the ozone values retrieved from the surface and from space: the change of the ozone absorption, mostly in the Huggins bands, with wavelength, is used to derive total and vertical profiles of ozone by remote sensing.

The apparatus developed at the University of Rome used a long absorption path and high ozone concentrations to measure very low absorption cross sections. One of the most challenging aspects of the experiment was the ability to produce a relatively large amount of ozone: it was produced by a high voltage discharge in a pure oxygen gas, and stored in the liquid phase at the liquid nitrogen temperature. Even the smallest impurity could start a fast reaction, leading to noisy explosions famous throughout the Department of Physics.

The ozonizer had to be rebuilt several times before all the measurements could be completed. Later on, measurements were extended also to $\mathrm{NO}_{2}$, a gas easier to handle than ozone (Amoruso et al., 1993).
At the same time, experiments on the detection of small changes of the refractive index of air were carried out with a Michelson interferometer (Crescentini and Fiocco, 1988).

The spectroscopic measurements were then moved to the Gran Sasso Laboratory. This large laboratory, built in the inner part of the Gran Sasso Mountain, $100 \mathrm{~km}$ east of Roma, shielded by approximately $1000 \mathrm{~m}$ of rock, is mainly dedicated to experiments in nuclear physics and astrophysics. At the time of the construction of the laboratory it was possible to foresee the use of some of the service tunnels for geophysical experiments (Fiocco et al., 1986). One of such experiments had to do with the deformation of rocks (Crescentini et al., 1997) and the detection of relatively slow phenomena like tides. For this purpose a Michelson $90 \mathrm{~m}$ long interferometer was ideal. The interferometer beams were to travel in a vacuum system. In addition to the geophysical metrology, the existence of a $90 \mathrm{~m}$ long pipe was useful for spectroscopy. To allow detailed measurements of very low absorption cross sections, a multi-pass cell was developed, and measurements of the $\mathrm{O}_{2}$ absorption in the Herzberg continuum were carried out (Amoruso et al., 1995, 1996).

At the University, of Rome, Giorgio Fiocco started to develop the lidars that were later deployed to different parts of the world forming something half-jokingly dubbed as the «small but global lidar network». These projects will be described later in this paper. At the same time, different experiments, including measurements on the boundary layer with a combination of different techniques (sodar, lidar, radiometers, etc.) were carried out (Rao et al., 1995; Casa-dio et al., 1996a,b; Rao et al., 2002).

In one of his pioneering studies, he suggested that clouds of different nature, possibly containing chemical compounds other than water (namely nitric acid), may form at the tropical tropopause (Crescentini and Fiocco, 1983; Hamill and Fiocco, 1988). Some of these studies were done well before the discovery of the ozone hole, and of the different properties and compositions of polar stratospheric clouds. The possible role of the condensation of nitric acid in cloud particles in the tropical regions was then evoked much later. 


\section{South Pole}

When the Italian government signed the Antarctic Treaty and officially joined the international program for research in Antarctica setting forth a call for proposals, Giorgio Fiocco did not wait long to deliver another original and challenging idea: the installation of a lidar at the Amundsen-Scott South Pole, station to monitor the presence of Polar Stratospheric Clouds (PSC's) during the austral winter. The Antarctic «ozone hole» phenomenon had been just confirmed by satellite measurements and theories implying the role of such clouds in the modification of the chemical reactions in the stratosphere were being proposed.

The project was not very simple; it implied the design of a reliable lidar system able to run without failures and as little as possible human attendance for several months. In particular, during the winter closure of the South Pole base, when the 10-20 personnel are mainly involved in staying healthy and safe, the only thing that can be required of the person in charge is throwing off and on a couple of switches. Any more technical intervention is out of the question. Such a system needs to be thoroughly tested in the laboratory, disassembled, transported to the site, reassembled, optically aligned and re-tested. The project started at the beginning of 1987 at the University of Rome with the aim of deploying the lidar around the following December; the lidar system was completely built from scratch, starting from the acquisition of the laser with a special cooling unit, to the construction of the telescope and the assembly of the electronics. In particular, the electronics, as was usual at that time, was made of a chain of different units originally designed for research in particle physics; the adjustment to a lidar system was not always simple. No need to say that it was a «tour de force» and not all the desirable tests were performed within the deadlines. Fiocco himself and his co-workers, within a collaboration with the U.S. National Oceanographic and Atmospheric Administration (NOAA) and the National Research Council (NRC), brought along $400 \mathrm{~kg}$ of equipment to the South Pole just before Christmas 1987, spent memorable holidays in the «southernmost place on Earth» and set up the lidar ready for measurements during the austral winter of 1988. Flying to the Amundsen-Scott station with the well maintained but quite old C-130 propeller airplanes with skis as landing gear is itself a pioneering deed and, even if well sheltered, whoever experienced the Antarctic katabatic winds knows it well. Beside the extreme cold, the South Pole is remarkable also for its height above sea level: more than $2600 \mathrm{~m}$ of geometrical altitude but, at those temperatures, equivalent to more than $3000 \mathrm{~m}$ according to ambient pressure. Giorgio Fiocco liked the adventure very much but did not like the height feeling and in his worries he enjoyed, in particular, the friendly reassurance of the base doctor. Such a close and somehow «interested» reassuring friendship with a doctor was seen again in another remote base where Fiocco went to deploy another of his lidars: U.S. Air Force Base of Thule, Greenland.

The first Antarctic campaign was mainly a test for the instrument but still a few data were collected. In the following years the instrument was maintained and updated and was able to work till 1995 when the project was discontinued and the lidar was brought back to Rome.

The collection of a rich and unique data set on PSC's allowed the publication of a fair amount of papers on several related topics (Fiocco et al., 1989, 1991, 1992, 1996; Fuà et al., 1992; Cacciani et al., 1993, 1997a,b; Panegrossi et al., 1996). In particular the paper of 1991 that encountered a strong criticism from the referees but was eventually published, presented a rather original and controversial way of interpreting the temperature dependence of PSC's to infer their chemical composition.

Following the eruption of Mt. Pinatubo (1991), it was possible to study the impact of the presence of a large amount of sulfate aerosol in the lower stratosphere on the formation and properties of the PSC's (Cacciani et al., 1997b).

\section{Thule}

In 1990, within a collaboration with the Danish Meteorological Institute a lidar was installed at Thule, Greenland. The lidar was designed to observe the upper troposphere and 
the stratosphere. Later the capability to make daytime observations, and to measure temperature profiles in the middle atmosphere, was added. The observations at Thule allowed the increasing and subsequent decaying phases of the stratospheric aerosol load formed by the eruption of volcano Pinatubo to be studied (Di Girolamo et al., 1994; Larsen et al., 1994; Neuber et al., 1994; Di Sarra et al., 1998a). The aerosol backscattering shows an evident annual cycle, induced by the polar vortex but also the influence of the large scale stratospheric circulation, mainly the QuasiBiennal Oscillation. Following previous studies conducted after the eruptions of Mt. Agung (Grams and Fiocco, 1967) and El Chichón (Adriani et al., 1987), an investigation of the relationship between volcanic aerosol and ozone in the lower stratosphere at Thule was also carried out (Di Sarra et al., 1992, 1995). The Arctic vortex strongly modulates the ozone and aerosol profiles, that display sudden changes with height, and an anti-correlated layered structure. A similar behavior had also been observed between PSC's and ozone at the South Pole (Fiocco et al., 1989). PSC's appeared occasionally also at Thule (Di Sarra et al., 2002).

Starting from 1993, temperature measurements were also collected at Thule (Marenco et al., 1997) and later a study was dedicated to the effects of small cirri at the summer Arctic tropopause (Benedetti et al., 1997).

\section{A lidar in the island of Lampedusa}

In 1999, the group led by Giorgio Fiocco installed a lidar for tropospheric aerosol studies at the Station for Climate Observations of the «Ente Nazionale per le Nuove Tecnologie, l'Energia e l'Ambiente» (ENEA) on the small and pleasant island of Lampedusa, placed between South Italy and Africa. The main objective of the measurements was the detection of desert dust transport over the Mediterranean. The desert dust strongly modifies the atmospheric structure, with large loads of crustal particles, that may reach altitudes of 7-8 km. The lidar observations (Di Sarra et al., 2001a) were carried out in combination with an extended set of other instruments, leading to the identification of the radiative effects (mainly in the ultraviolet spectral range) induced by the aerosol (Di Sarra et al., 2001b).

\section{An airborne lidar}

As the South Pole project was approaching its completion, Giorgio Fiocco, in his search for new and challenging experiences, began to develop an airborne lidar which would be installed onboard the scientific version of the Myasishchev stratospheric aircraft M-55, Geophysica. The lidar was named ABLE (AirBorne Lidar Experiment). ABLE is a completely automated, medium-power lidar capable of operating in an unpressurized, cold environment such as that of Geophysica, observing in the nadir and in the zenith direction. The development of this kind of instrument that works in very extreme ambient conditions requires considering different problems and constraints: weight, strength, thermal stresses, low pressure, humidity condensation are just few of the problems faced in the process. Giorgio Fiocco was totally at ease spending hours in front of the drawing board trying all kind of solutions or discussing with the ever present machinist on the way to finish a part of the lidar. Little by little, a jewel of aluminium looking like a fancy space object blossomed in the laboratory. We should mention also the frequent, tiring, neverending and babilonian (languagewise) meeting with the team of Russian engineers in charge of the aircraft.

In summer of 1996, the mock-up of ABLE was installed for the first time on the M-55, which took off from Zukhovsky airport, Russia, in order to check how ABLE would behave in real flight conditions. In fact, the Geophysica usually flies at $20 \mathrm{~km}$ forcing ABLE to work at pressure of $50 \mathrm{mb}$ (one twentieth of atmospheric pressure at sea level) and at a temperature ranging between 190-200 K (approximately 80 $0^{\circ}$ below freezing point) (Fiocco et al., 1999).

In winter 1996-1997, ABLE was flown to Rovaniemi, Finland, which had been selected as the base for the first measurement campaign of Geophysica. The campaign was named APEPOLECAT (Airborne Polar Experiment-Polar Ozone, Lee waves, Chemistry And Transport) (Stefanutti et al., 1999; Pace et al., 2003a). 
Then other campaigns followed: APE-THESEO (Airborne Platform Experiment - THird European Stratospheric Experiment on Ozone) based at the airport of Victoria-Mahé, Seychelles (Pace et al., 2003b), APE-GAIA (Geophysica Aircraft In Antartica) based at the airport of Ushuaia in Terra del Fuoco, Argentina, EUPLEX (EUropean Polar stratospheric cloud and LEe wave Experiment) based at Kiruna (Sweden) and the ENVISAT (ENVironment SATellite) validation campaign based at Forlì (Italy) and at Kiruna (Sweden). The location of Ushuaia permitted the aircraft to fly across the polar vortex down to the Antarctic peninsula approaching $70^{\circ}$ south.

It is noteworthy that during the campaign in the Seychelles, in order to support the operation of ABLE and acquire independent ground based lidar observations of high equatorial cirrus clouds also a twin lidar housed in a container was deployed: CABLE, a self contradicting acronym originating from the words «Container» plus «ABLE». The «small but global lidar network» still rising!

Fiocco is now participating in the proposal to fly a lidar in the International Space Station in a complex venture with Livio Scarsi called EUSO and described in one of the papers of this issue.

Recently, the external and internal structure of the receiver of ABLE has been totally redesigned and built to reduce its weight and make it resemble more a submarine robot. We all believe that the final goal of this small but complex lidar system is to fly sometimes in a space payload, but nobody is officially stating it because changing the «A» with another meaningful utterable letter is too difficult. The ABLE project is still going on and absorbs much of Giorgio Fiocco's time (and research funds): it is indeed the present enjoyable toy and needful thing of such a good ol' fellow.

\section{REFERENCES}

Ackerman, M., C. Brogniez, B. Diallo, G. Fiocco, G.P. GobBi, M. HeRman, M. JAeGer, J. LenOble, C. LiPPENS, C. MEGIE, J. PELON, R. REITER and R. SANTER (1988): European validation of SAGE II aerosol profiles, J. Geophys. Res., 94, 8399-8411.

ADAM, A.M. and G. FIOCCO (1959): Automatic device for following an assigned course, Marconi's Co., Baddow Res. Lab., ITM 598.
Adriani, A., F. Congeduti, G. Fiocco and G.P. GobBi (1983): One-year lidar observations of the stratospheric aerosol layer following the El Chichón eruption, Geophys. Res. Lett., 10, 1005-1008.

Adriani, A., G. Fiocco, G.P. GobBi and F. Congeduti (1987): Correlated behaviour of the aerosol and the ozone content of the stratosphere after the El Chichón eruption, J. Geophys. Res., 92, 8365-8372.

Amoruso, A., M. CACCIANi, A. Di SARra and G. Fiocco (1990): Absorption cross sections of ozone in the 590- to 610-nm region at $T=230 \mathrm{~K}$ and $T=299 \mathrm{~K}, J$. Geophys. Res., 95, 20,565-20,568.

Amoruso, A., L. Crescentini, G. Fiocco and M. VolPe (1993): New measurements of the $\mathrm{NO}_{2}$ absorption crossection in the 440-to 460-nm region and estimates of the $\mathrm{NO}_{2}-\mathrm{N}_{2} \mathrm{O}_{4}$ equilibrium constants, J. Geophys. Res., 98, $16,857-16,863$.

Amoruso, A., L. CRESCENTINI and G. FiocCO (1995): Longbase-line multiple reflection cell for UV and visible spectroscopy, Rev. Sci. Instrum., 66, 4824-4826.

Amoruso, A., L. Crescentini, M.S. ColA and G. FiocCO (1996): Oxygen absorption cross-section in the Herzberg continuum, J. Quant. Spectrosc. Radiat. Transfer, 56, $145-152$.

Benedetti, A., A. Di SARra, G. FiocCo and D. FuÀ (1997): Cirrus clouds at Thule, Greenland, during summer: lidar observations and influence on the planetary radiative budget, in IRS '96, Current Problems in Atmospheric Radiation, edited by W.L. SMITH and K. STAMNES (A. Deepak, Hampton, Va), 23-26.

Benedetti-Michelangeli, G., F. Congeduti and G. FIOCCO (1972): Measurements of aerosol motion and wind velocity in the lower troposphere by Doppler optical radar, J. Atmos. Sci., 29, 906-910.

Benedetti-Michelangeli, G., F. Congeduti and G. FIOCCO (1974): Determination of vertical eddy diffusion parameters by Doppler optical radar, Atmos. Environ., 8, 793-799.

CACCiani, M., G. Di SARra, G. Fiocco and A. Amoruso (1989): Absolute determination of the cross sections of ozone in the wavelength region $339-355 \mathrm{~nm}$ at temperatures 220-293 K, J. Geophys. Res., 94, 8485-8490.

CACCIANi, M., P. Di Girolamo, A. Di SARRA, G. FiocCO and D. FUÀ (1993): Volcanic aerosol layers observed by lidar at South Pole, September 1991-June 1992, Geophys. Res. Lett., 20, 807-810.

CACCIANi, M., G. Fiocco, P. Colagrande, P. Di Girolamo, A. DI SARRA and D. FUÀ (1997a): Lidar observations of polar stratospheric clouds at the south pole. 1 . stratospheric unperturbed conditions, 1990, J. Geophys. Res., 102, 12,937-12,943.

Cacciani, M., P. Colagrande, A. Di Sarra, D. FuÀ, P. Di GIROLAMO and G. FIOCCO (1997b): Lidar observations of polar stratospheric clouds at the south pole. 2: stratospheric perturbed conditions, 1992 and 1993, J. Geophys. Res., 102, 12,945-12,955.

CASAdio, S., A. Di SARRA, D. FuÀ, M.P. RAO and G. FiOCCO (1996a): Raman lidar and Doppler sodar observations of the nocturnal boundary layer at Rome, Italy, during 1994 and 1995, in Advances in Atmospheric Remote Sensing with Lidar, edited by A. ANSMANN, R. NEUBER, 
P. RAIROUX and U. WANDINGER (Springer-Verlag, Berlin), 27-30.

Casadio, S., A. Di Sarra, G. Fiocco, D. Fuà, F. LenA and M.P. RAO (1996b): Convective characteristics of nocturnal urban boundary layer observed with Doppler sodar and Raman lidar, Boundary Layer Meteorol., 79, 375-391.

Congeduti, F., G. FIOCCO, A. Adriani and C. GuARrella (1981): Vertical wind velocity measurements by a Doppler lidar and comparisons with a Doppler sodar, Appl. Opt., 20, 2048-2054.

ConNES, P. (1958): L'etalon de Fabry-Perot sphèrique, $J$. Phys. Radium, 19, 262.

Crescentini, L. and G. FiocCO (1983): Possible effects of stratospheric aerosol layers on the vertical transport of water, Nuovo Cimento, 6C, 337-349.

Crescentini, L. and G. FIOCCO (1988): Automatic fringe recognition and detection of subwavelength phase perturbations with a Michelson interferometer, Appl. Opt., 27, 118-123.

Crescentini, L., A. Amoruso, G. Fiocco and G. Visconti (1997): Installation of a high-sensitivity laser strainmeter in a tunnel in Central Italy, Rev. Sci. Instrum., 68, 32063210.

Di Girolamo, P., M. CACCIANi, A. Di SARRA, G. FiocCo and D. FUÀ (1994): Lidar observations of the Pinatubo aerosol layer at Thule, Greenland, Geophys. Res. Lett., 21, 1295-1298.

Di SARra, A., M. Cacciani, P. Di Girolamo, G. Fiocco, D. FuÀ, B. KNUDSEN, N. LARSEN and T.S. JøRGENSEN (1992): Observations of correlated behaviour of stratospheric ozone and aerosol at Thule during winter 1991-1992, Geophys. Res. Lett., 19, 1823-1826.

di Sarra, A., M. Cacciani, G. Fiocco, D. FuÀ, T.S. JøRGENSEN, B. KNUDSEN, N. LARSEN and I.S. MiKKELSEN (1995): Ozone and aerosol correlated observations at Thule, Greenland, in the period 1991-1994, J. Geophys. Res., 100, 25,965-25,977.

Di Sarra, A., L. Bernardini, M. Cacciani, G. FiocCo and D. FUÀ (1998a): Lidar observations of the Pinatubo aerosol at Thule, in Greenland: relationships with the polar vortex, in Atmospheric Ozone, edited by R. BOJKOV and G. VisCONTI, Parco. Sci. Tecnol. d'Abruzzo, L'Aquila, Italy, 197-200

DI SARRA, A., L. BERNARDINI, M. CACCIANI, G. FiOCCO and D. FUÀ (1998b): Stratospheric aerosol observed by lidar over Northern Greenland in the aftermath of the Pinatubo eruption, J. Geophys. Res., 103, 13,873-13,891.

DI SARRA, A., T. DI IORIO, M. CACCIANI, G. FIOCCO and D. FUÀ (2001a): Saharan dust profiles measured by lidar at Lampedusa, J. Geophys. Res., 106, 10,335-10,347.

Di SARra, A., M. CACCIANI, M. CAMPANELli, P. ChAMARD, C. Cornwall, J. Deluisi, L. De Silvestri, T. Di IORIO, P. Disterhoft, G. FiOCCO, D. FuÀ, P. GRIGIONI, W. Junkermann, F. Marenco, D. Meloni, F. MONTELEONE and B. Olivieri (2001b): Radiation, ozone, and aerosol measurements at Lampedusa during the PAUR II Campaign, in IRS 2000: Current Problems in Atmospheric Radiation, edited by W.L. SMITH and Yu.M. TIMOFEYEV (A. Deepak Publishing, Hampton, Virginia), 1193-1196.
Di Sarra, A., M. Cacciani, G. Fiocco, D. FuÀ and T.S. JØRGENSEN (2002): Lidar observations of polar stratospheric clouds over Northern Greenland in the period 1990-1997, J. Geophys. Res., 107 (AAC6), 1-16.

FiocCO, G. (1958a): Comparison of some published data on sea and land reectivity, Marconi's Co., Baddow Res. Lab., ITM 299.

FIocCO, G. (1958b): Notes on integrated Doppler-inertia navigational systems, Marconi's Co., Baddow Res. Lab., ITM 342.

FIOCCO, G. (1958c): A method of evaluating and correcting for calibration errors in Doppler navigational systems, Marconi's Co., Baddow Res. Lab., ITM 352.

FIOCCO, G. (1958d): A method of range determination using FM, Marconi's Co., Baddow Res. Lab., ITM 391.

FIOCCO, G. (1958e): Echoes from rain in Doppler navigational systems, Marconi’s Co., Baddow Res. Lab., ITM 394.

FiocCO, G. (1959a): A note on the use of harmonic bands of high order in FM Doppler systems, Marconi's Co., Baddow Res. Lab., ITM 434.

FIOCCO, G. (1959b): FM altimeter; a preliminary investigation, Marconi’s Co., Baddow Res. Lab., ITM 555.

FIOCCO, G. (1959c): British Patent 871656, improvements in or relating to Doppler Radar Systems, British Patent Office.

FIOCCO, G. (1959d): British Patent 869809, improvements in or relating to Radar Systems, British Patent Office.

FIOCCO, G. (1959e): British Patent 869808, improvements in or relating to Radar Systems, British Patent Office.

FiocCO, G. and G. COLOMBO (1964): Optical radar results and meteoric fragmentation, J. Geophys. Res., 69, 1975.

FIOCCO, G. and B.J. DE WOLF (1968): Frequency spectrum of laser echoes from atmospheric constituents and determination of the aerosol content of air, J. Atmos. Sci., 25, 488-496.

FIOCCO, G. and G.W. GRAMS (1964): Observations of the aerosol layer at $20 \mathrm{~km}$ by optical radar, J. Atmos. Sci., 21, 323-324.

FiocCO, G. and G.W. GRAMS (1966): Observations of the upper atmosphere by optical radar in Alaska and Sweden during the summer of 1964, Tellus, 18, 34-38.

FIOCCO, G. and G.W. GRAMS (1969): Optical radar observations of mesospheric aerosols in Norway during the summer 1966, J. Geophys. Res., 74, 2453-2458.

FiocCO, G. and G.W. GRAMS (1971): On the origin of noctilucent clouds: extraterrestrial dust and trapped water molecules, J. Atmos. Terr. Phys., 33, 815-824.

FiocCO, G. and G. MASTRANTONIO (1983): Characters of the air flow inferred from detailed spectral analysis of acoustic sounder echoes, J. Acoust. Soc. Am., 74, 1861-1865.

Fiocco, G. and G. Visconti (1973): On the seasonal variation of upper atmospheric sodium, J. Atmos. Terr. Phys., 35, 165-171.

FIOCCO, G. and G. VisCONTI (1974): Simultaneous measurements of the $\mathrm{OH}^{*}$ nightglow in the (9-4), (8-3) and (5-1) bands and effects of quenching, J. Atmos. Terr. Phys., 36, 583-590.

FIOCCO, G. and L.D. SMULLIN (1963): Detection of scattering layers in the upper atmosphere $(60-140 \mathrm{~km})$ by optical radar, Nature, 199, 1275-1276. 
FiOcCO, G. and E. ThOMPSON (1963): Thomson scattering of optical radiation from an electron beam, Phys. Rev. Lett., 10, 89.

Fiocco, G., G. Visconti and F. Congeduti (1970): Nocturnal variation of the intensity and rotational temperature of the $\mathrm{OH}(8-3)$ band in the airglow, Nature, 228, 1079.

Fiocco, G., G. BenEdetti-Michelangeli, K. MAischBerGER and E. MADONNA (1971): Measurement of temperature and aerosol-to-molecule ratio in the troposphere by optical radar, Nature, 229, 78-79.

FIOCCO, G., D. FUÀ and G. VISCONTI (1974): Origin of the upper Atmosphere Na from sublimating dust: a model, Annal. Geophys., 30, 517-528.

FIOCCO, G., G. GRAMS and G. VISCONTI (1975): Equilibrium temperatures of small particles in the Earth's upper atmosphere (50-110 km), J. Atmos. Terr. Phys., 37, $1327-1337$.

FiocCO, G., G. GRAMS and A. Mugnai (1976): Energy exchange and temperature of aerosols in the Earth's atmosphere (0-60 km), J. Atmos. Sci., 33, 2415-2424.

FiocCO, G., A. MugNAI and W. ForLIZZI (1978): Effects of radiation scattered by aerosols on the photodissociation of ozone, J. Atmos. Terr. Phys., 40, 949-961.

Fiocco, G., G. Visconti and G.P. CATAlano (1986): Interferometria laser per la misura delle deformazioni della crosta terrestre: progetto della Stazione del Gran Sasso, Nuovo Saggiatore, 2, 25-27.

Fiocco, G., W. Komhyr and D. FuÀ (1989): Is ozone destroyed during the Antarctic polar night in the presence of polar stratospheric clouds?, Nature, 341, 426-427.

Fiocco, G., D. FuÀ, M. CACCIANI, P. Di GiRolamo and J. DELUISI (1991): On the temperature dependence of polar stratospheric clouds, Geophys. Res. Lett., 18, 424-427.

Fiocco, G., M. Cacciani, P. Di Girolamo and D. FuÀ (1992): Stratospheric clouds at South Pole during 1988: 1. Results of lidar observations and their relationship to temperature, J. Geophys. Res., 97, 5939-5946.

Fiocco, G., M. CaCcIani, A. Di SARRA, D. FuÀ, P. CoLagrande, G. De Benedetti, P. Di Girolamo and R. ViOLA (1996): The evolution of the Pinatubo stratospheric aerosol layer observed by lidar at South Pole, Rome, Thule: a summary of results, in The Effects of the Mt. Pinatubo Eruption of the Atmosphere and Climate, edited by G. FIOCCO, D. FUÀ and G. VISCONTI, NATO/ASI Series.

Fiocco, G., P.G. CAlisse, M. CACCIANI, S. CASAdio, G. PACE and D. FUÀ (1999): ABLE: development of an airborne lidar, J. Atmos. Ocean. Technol., 16, 1337-1344.

FuÀ, D., M. CACCIANI, P. Di GiROlAMO, G. FiocCO and A. Di SARRA (1992): Stratospheric clouds at South Pole during 1988. 2: their evolution in relation to atmospheric structure and composition, J. Geophys. Res., 97, 5947-5952.

Grams, G.W. and G. FIOCCO (1967): The stratospheric aerosol layer in 1964 and 1965, J. Geophys. Res., 72, 3497-3542.

GRAMS, G.W. and G. FIOCCO (1977): Equilibrium temperatures of spherical ice particles in the upper atmosphere and implications for noctilucent cloud formation, $J$. Geophys. Res., 82, 961-966.
HAMiLl, P. and G. FIOCCO (1988): Nitric acid aerosols at the tropical tropopause, Geophys. Res. Lett., 15, 11891192.

Horn-D'Arturo, G. (1935): Primi esperimenti con lo specchio a tasselli, Pubbl. Oss. Bologna, Vol. III, n. 3.

LARSEN, N., B. KNUDSEN, T.S. JøRGENSEN, A. Di SARRA, D. FuÀ, P. Di Girolamo, G. Fiocco, M. Cacciani, J.M. Rosen and N.T. KJOME (1994): Backscatter measurements of stratospheric aerosols at Thule during January-February 1992, Geophys. Res. Lett., 21, 13031306.

Marenco, F., A. Di Sarra, M. Cacciani, G. Fiocco and D. FUÀ (1997): Thermal structure of the winter middle atmosphere observed by lidar at Thule, Greenland, during 1993-94, J. Atmos. Terr. Phys., 59, 151-158.

Mastrantonio, G. and G. Fiocco (1982): Accuracy of wind velocity determinations with Doppler sodars, $J$. Appl. Meteorol., 21, 823-830.

Mugnai, A., G. FiocCo and G. Grams (1978): Effects of aerosol optical properties and size distributions on heating rates induced by stratospheric aerosols, $Q$. J. R. Meteorol. Soc., 104, 783-796.

Mugnai, A., P. Petroncelli and G. Fiocco (1979): Sensitivity of the photodissociation of $\mathrm{NO}_{2}, \mathrm{NO}_{3}$, and $\mathrm{H}_{2} \mathrm{O}_{2}$, to the solar radiation diffused by the ground and by atmospheric particles, J. Atmos. Terr. Phys., 41, 351-359.

Neuber, R., G. Beyerle, G. Fiocco, A. Di SARra, K.H. Fricke, C. David, S. Godin, L. Stefanutti, G. VAUGHAN and J.P. WOLF (1994): Latitudinal distribution of stratospheric aerosols during the EASOE winter 1991/92, Geophys. Res. Lett., 21, 1283-1286.

Pace, G., M. Cacciani, P.G. Calisse, A. Di Sarra, G. FIOCCO, D. FUÀ, L. RINALDI and S. CASADIO (2003a): Observation of polar stratospheric clouds with the ABLE lidar during the APE-POLECAT flight of January 9, 1997, Aerosol Sci. (in press).

PACE, G., M. CACCIANI, A. DI SARRA, G. FiOCCO and D. FuÀ (2003b): Lidar observations of equatorial cirrus clouds at Mahé, Seychelles, J. Geophys. Res. (in press).

PANEGROSsi, G., D. FUÀ and G. FiocCo (1996): A 1D model of the formation and evolution of polar stratospheric clouds, J. Atmos. Chem., 23, 5-35.

PARKIN, D.W. and D. TILLES (1968): Influx measurements of extraterrestrial material, Science, 159, 936-946.

Petroncelli, P., G. Fiocco and A. Mugnai (1980): Annual variation of the effects of diffuse radiation on the photodissociation of ozone, Pure Appl. Geophys., 118, 20-34.

RaO, M.P., S. CASAdio, G. Fiocco, F. Lena, M. CACCIANI, P.G. CAlisse, A. DI SARRA and D. FuÀ (1995): Observation of lump structures in the nocturnal atmospheric boundary layer with Doppler sodar and Raman lidar, Geophys., Res. Lett., 22, 2505-2508.

RAO, M.P., S. CASADIO, G. FIOCCO, M. CACCIANI, A. DI SARRA, D. FuÀ and P. CASTRACANE (2002): Estimation of atmospheric water vapor flux profiles in the nocturnal unstable urban boundary layer with Doppler sodar and Raman lidar, Boundary Layer Meteorol., 102, 39-62.

SMULLIN, L.D. and G. FIOCCO (1962): Optical echoes from the Moon, Nature, 194, 1267. 
Stefanutti, L., A.R. MacKenZie, S. BALestri, V. Khattatov, G. Fiocco, E. Kyroe and T. Peter (1999): Airborne Polar Experiment-Polar ozone, Leewaves, Chemistry, and Transport (APE-POLECAT): rationale, road map and summary of measurements, J. Geophys. Res., 104, 23,941-23,959.

ViscONTI, G. and G. FIOCCO (1970): Sodium twilight emission measured with a tilting filter photometer, Pure Appl. Geophys., 9, 2517.

VISCONTI, G. and G. FIOCCO (1973): Increase of Na twilight emission after the Earth's crossing of the orbital planes of Comets Halley and Encke, J. Atmos. Terr. Phys., 35, 353-356.

Visconti, G., F. Congeduti and G. Fiocco (1971): Fluc-tuations in the intensity and excitation temperature in the $\mathrm{OH}$ airglow (8-3) band, in The Radiating Atmosphere, edited by B.M. MCCORMAC (D. Reidel Publishing Company, Dordrecht, Holland), 82-89.

ZucCheretTi, E., D. FuÀ and G. FiocCo (1992): A laserslaved piezo-controlled Fabry-Perot interferometer, Rev. Sci. Instr., 63, 2940-2944. 